\title{
ANÁLISE SOCIOAMBIENTAL A PARTIR DOS ZONEAMENTOS ECOLÓGICO ECONÔMICO DA ÁREA DE PROTEÇÃO AMBIENTAL DAS LAGOAS E DUNAS DO ABAETÉ
}

\author{
URBAN ENVIRONMENTAL ANALYSIS STARTING FROM FREQUENT CHANGES IN ECOLOGICAL ECONOMIC \\ ZONING OF ENVIRONMENTAL PROTECTION AREA AT THE LAGOAS AND DUNES OF ABAETÉ
}

\author{
Vivian de Oliveira Fernandes \\ Universidade Federal da Bahia (UFBA), Salvador, BA, Brasil, vivian.deofernandes@gmail.com \\ Iran Carlos Caria Sacramento \\ Centro Universitário Jorge Amado (UNIJORGE), Salvador, BA, Brasil, iransacramento@hotmail.com \\ Patricia Lustosa Brito \\ Universidade Federal da Bahia (UFBA), Salvador, BA, Brasil, britopatricia@hotmail.com \\ Mauro José Alixandrini Júnior \\ Universidade Federal da Bahia (UFBA), Salvador, BA, Brasil, mauro.alixandrini@gmail.com
}

\begin{abstract}
RESUMO
As áreas de Proteção Ambiental em espaços urbanos sofrem temporalmente com o crescimento das cidades. Na maioria dos casos, o crescimento desenfreado das cidades aparece como um dos agentes da degradação. Entendendo que o dilema da degradação ambiental é responsabilidade tanto dos cidadãos, órgãos governamentais, como de diversos setores produtivos da economia, é necessário que todos possam contribuir para diminuição dos impactos de suas ações no meio ambiente. Desta maneira, este trabalho tem como objetivo apresentar a evolução relacionada às mudanças do Zoneamento Ecológico Econômico (ZEE) da Área de Proteção Ambiental das Lagoas e Dunas do Abaeté a partir de sua institucionalização em 1987. A metodologia contou com a análise de imagens temporais do ano de 1976 a 2010. Neste processo foram produzidos mosaicos a partir de aerofotos aos quais foram aplicadas técnicas de fotointerpretação para delimitação da Área de Proteção Ambiental (APA). Posteriormente às delimitações, foram construídos mapas temáticos que serviram de suporte para o cruzamento de informações que contribuíram para apontar constatações de alterações na vegetação, na geomorfologia, geologia, no equilíbrio hídrico e na ocupação urbana desordenada. Concluí-se que a APA do Abaeté em um período de 18 anos teve uma redução de 75,35 ha de sua área e a necessidade de aplicação de programas de educação ambiental eficientes com todos aqueles que vivem e a frequentam.
\end{abstract}

Palavras-chave: Zoneamento Ecológico Econômico (ZEE); Área de Proteção Ambiental; Geotecnologias.

\begin{abstract}
Environmental Protection in urban areas suffer temporally with the growth of cities. In most cases the uncontrolled growth of cities appears as one of the agents of degradation. Understanding the dilemma of environmental degradation is the responsibility of both the citizens, government agencies such as the various productive sectors of the economy, it is important that everyone can contribute to mitigation of the impacts of their actions on the environment. Thus, this work aims to present the developments related to the changing of the Environmental Protection Area of ponds and dunes of Abaete Ecological-Economic Zoning (ZEE) from its institutionalization in 1987 The methodology included the analysis of temporal images years 1976 and 2010 this process mosaics were produced from aerial photographs which image interpretation techniques for delineation of the Environmental Protection area (APA) were applied. Later the boundaries, thematic maps that would support cross-point information that contributed to findings of changes in vegetation, in geomorphology, geology, and water balance in the cluttered urban settlements were built. It is concluded that the APA had Abaete in a period of 18 years from the APA Abaete decreased by 75.35 ha of the area and the need for efficient application of environmental education programs with all those who live and frequent the area studied.
\end{abstract}

Keywords: Ecological-economic zoning (EEZ); Environmental Protection Area; Geotechnologies.

Artigo recebido para publicação em outubro de 2014

Artigo aceito para publicação em agosto de 2015

\section{INTRODUÇÃO}


O espaço social visto como fruto das relações sociais, além da transformação material pelo processo de trabalho, a territorialização e urbanização através de projeções de poder e a atribuição de significados culturais. Desta forma, a cidade é um ambiente construído artificial, implicando em impactos sobre o espaço natural, o assim chamado "meio ambiente", que quanto maior e mais complexa for a urbe, maiores serão seus impactos ao meio ambiente.

Verifica-se atualmente nas metrópoles um agravamento das condições de moradia das populações de baixa renda - um processo de periferização do crescimento metropolitano, acompanhado de um aumento significativo nos índices de "favelização" - e um grau devastador de degradação ambiental provocado por loteamentos ilegais e ocupações sobre áreas protegidas.

A significativa concentração da pobreza nas metrópoles brasileiras tem como expressão um espaço dual: de um lado a cidade formal, que concentram os investimentos públicos e do outro lado, a cidade informal, que cresce exponencialmente na ilegalidade urbana. A precariedade e a ilegalidade são seus componentes genéricos e contribuem para a formação dos sistemas urbanos sem um escalonamento de suas variáveis.

A degradação ambiental está associada não apenas à produção de riqueza, mas também a outra vertente do capitalismo: a pobreza. Assim, cabe chamar a atenção para a relação de causa e efeito entre estas variáveis com a degradação ambiental ou mais amplamente, para o círculo vicioso da pobreza que leva a deteriorização do meio ambiente, que por sua vez está intimamente ligado a segregação sócio-espacial.

Sendo a degradação ambiental responsabilidade tanto das pessoas comuns como dos órgãos governamentais e dos diversos setores produtivos da economia, é importante que todos possam contribuir para diminuir o impacto negativo de suas ações ao meio ambiente, colaborando com diversas 
atitudes, constituindo formas de manejo que proporcionem a qualidade e possibilidade de vida não só para as gerações atuais, mas para as gerações que ainda estão por vir.

Desta forma, este trabalho tem o objetivo de apresentar a análise ambiental urbana em virtude das freqüentes mudanças nas áreas e limites da Área de Proteção Ambiental das Lagoas e Dunas do Abaeté no Zoneamento Ecológico Econômico (ZEE), percebendo os avanços da degradação ambiental, utilizando ferramentas de Geotecnologias, num estudo entre os anos de 1976 e 2010.

Neste intuído, escolheu-se como parâmetro de validação e desenvolvimento desta dissertação a região da APA das Lagoas e Dunas do Abaeté, local pelo qual em sua cotidianidade luta contra as mazelas do crescimento urbano e que possui como fonte reguladora o seu Zoneamento Ecológico Econômico.

Considerando os avanços tecnológicos associados ao desenvolvimento das ferramentas de apoio ao planejamento urbano, bem como, as diversas formas de análises do crescimento urbano nas cidades, busca-se uma compreensão específica na tentativa de entender e esclarecer como as cidades estão crescendo, e através deste, analisar as propostas das legislações ambientais que envolvem as esferas estadual e municipal e se as leis propostas para elas realmente estão sendo pré-estabelecidas e seguidas por sua população.

O objetivo primordial de uma APA é a conservação de processos naturais e da biodiversidade, orientando o desenvolvimento, adequando as várias atividades humanas às características ambientais da área.

\section{REFRENCIAL TEÓRICO}

O zoneamento é um instrumento amplamente utilizado nos planos diretores, através do qual a cidade é dividida em áreas sobre as quais incidem diretrizes para o uso e a ocupação do solo, especialmente os índices urbanísticos. O zoneamento foi utilizado pela primeira vez na Alemanha, mas foi nos Estados Unidos que ele ganhou força, a partir do início do século XX Alguns de seus principais objetivos são: 
controle do crescimento urbano; proteção de áreas inadequadas à ocupação urbana; minimização dos conflitos entre usos e atividades; controle do tráfego; manutenção dos valores das propriedades e do status quo. (JUERGENSMEYER; ROBERT, 2003).

Entre as Geotecnologias utilizadas para o desenvolvimento desta pesquisa pode-se citar a utilização de Sistemas de Informações Geográficas (SIG) para a manipulação e auxílio a análise das informações adquiridas através da utilização de aerofotos, imagens de satélite e imagens fotográficas coletadas no local de estudo. Os sistemas de informações geográficas são utilizados para manipular, sintetizar, editar e visualizar informações, geralmente armazenadas em bases de dados computacionais. O SIG utiliza informações espaciais sobre o que está/ou ocorre na superfície da Terra, ou seja, é um poderoso conjunto de ferramentas para coleta, armazenamento e recuperação de dados espaciais do mundo real (BURrough, P. A. e MCDOnNell, R. A., 1998). Para Câmara et al. (2001) o termo SIG, é aplicado para sistemas que realizam o tratamento computacional de dados geográficos e armazenam a geometria e atributos dos dados que estão georreferenciados, isto é, localizados na superfície terrestre e representados numa projeção cartográfica (CAMARA, 2001). Para Pereira e Silva (2001), os SIGs podem ser considerados como modelos de sistemas do mundo real e além de serem modelos que cumprem "as funções dos modelos convencionais (mapas, maquetes), acrescentam novos horizontes às atividades de análise, planejamento, projeto e gestão".

Considerando a importância da coleta de dados para as devidas aplicações e auxílio para o desenvolvimento científico, esta atividade sempre foi de grande importância nas sociedades organizadas. Entretanto, até outrora, essas análises eram realizadas de maneira manual (com mapas e documentos analógicos) e em alguns casos primitivas, o que impedia uma eficácia no cruzamento destas informações. Com o passar do tempo e a explosão tecnológica na segunda metade do século XX, tornou-se possível armazenar e representar as informações em um ambiente digital.

Com este avanço tecnológico e as diversas formas de coleta e representação dos dados na atualidade, a importância da utilização das ferramentas de SIG em variadas áreas de conhecimento 
proporcionou surgimento das Geotecnologias como uma generalização de todas estas ferramentas que compõe o Sistema de Informação Geográfica.

Num país como o Brasil, com vários problemas sociais e uma grande deficiência no que podemos relacionar a informações apropriadas nas decisões de cunho urbano, ambiental e social, as Geotecnologias, oferecem um admirável potencial, pois, com custo relativamente baixo e com tecnologia de ponta, torna-se possível a automatização e a elaboração de diversos produtos cartográficos.

Assim segundo ROSA (2005), as Geotecnologias podem ser definidas como "Um conjunto de tecnologias para coleta, processamento, análise e oferta de informações com referência geográfica. As Geotecnologias são compostas por soluções em hardware, software e peopleware que juntos constituem poderosas ferramentas para tomada de decisões. Dentre as Geotecnologias podemos destacar: sistemas de informação geográfica, cartografia digital, sensoriamento remoto, sistema de posicionamento global e a topografia."

Estas geotecnologias são instrumentos notáveis na delimitação das APA. A presença de riquezas naturais e a necessidade de proteger os ecossistemas locais do impacto das atividades humanas culminam na proposta da criação das Áreas de Preservação Ambiental. Em linhas gerais, esta iniciativa tem por objetivo de promover uma integração harmoniosa entre atividades produtivas de uma região e a conservação da natureza, buscando o uso sustentável dos recursos naturais e melhores condições de vida para a população local.

\section{CARACTERIZAÇÃO DA ÁREA DE ESTUDO}

“A APA do Abaeté está localizada entre as coordenadas geográficas $38^{\circ} 25{ }^{\prime} 01$ ” W, $12^{\circ} 56^{\prime} 13^{\prime} \mathrm{S}$ e $38^{\circ} 21^{\prime} 55.09^{\prime \prime} \mathrm{W}, 12^{\circ} 56^{\prime} 58.36$ "S, ocupando uma área de 1.241 hectares conforme a figura 1 . 


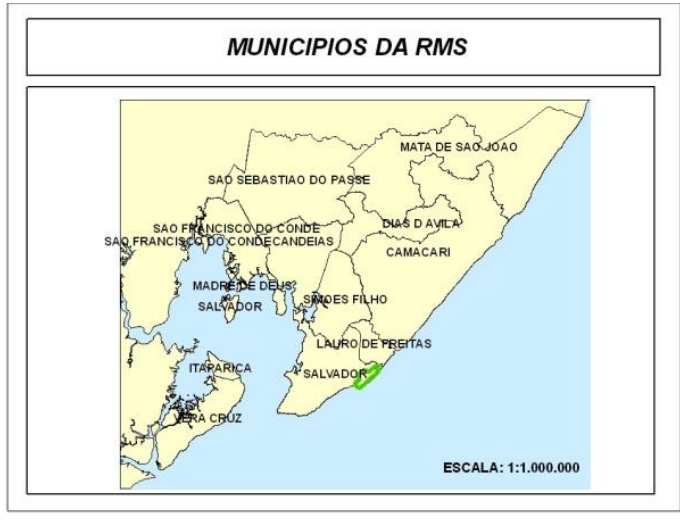

DIVISÃO DE BAIRROS E SETORES CENSITÁRIOS

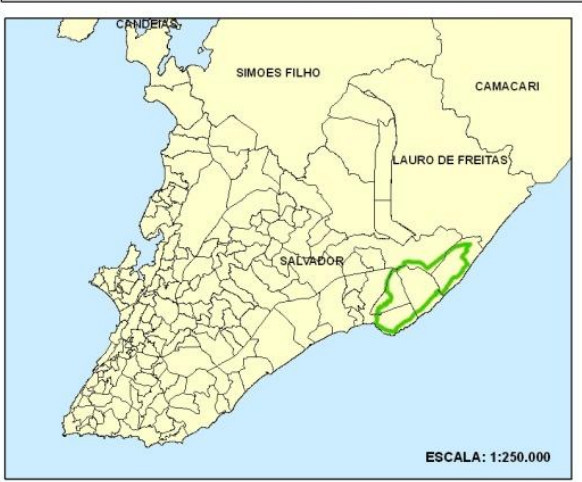

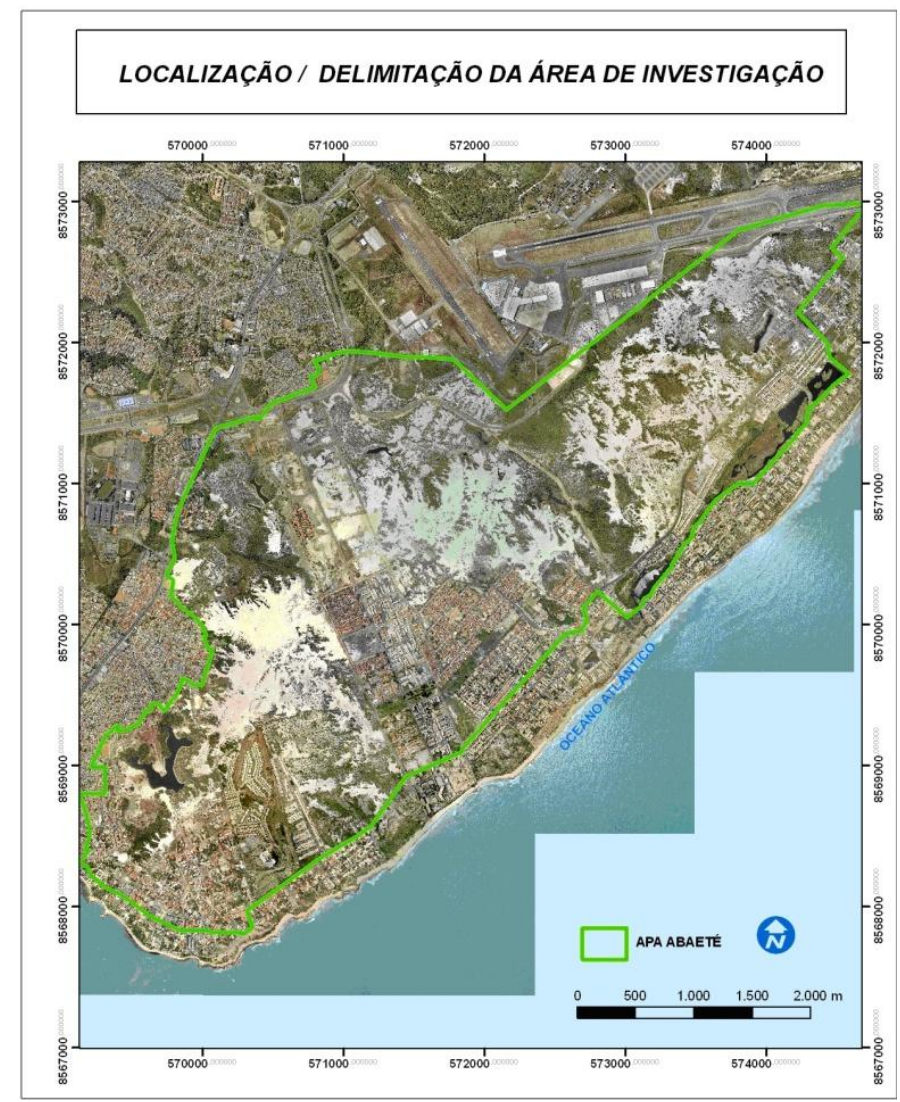

Figura 1. Localização da área de estudo.

Fontes: CONDER, 1992 e PMS, 2006

A APA do Abaeté tem como características geoambientais o clima característico da cidade de Salvador, classificado de acordo com o sistema de Köppen, é Tropical, quente úmido e sem estação seca (Martin et al., 1980). Justamente pelo fato da região estar localizada entre o Trópico de Capricórnio e a Linha do Equador. Apresentando uma precipitação média anual de 1950 milímetros. Contudo, ocorre uma variabilidade de precipitação anual, chegando a 350 milímetros no mês de maio e 70 milímetros no mês de janeiro (INMET, 1990).

Há predomínio de ventos alísios do quadrante E, soprando na direção SE, durante o outono e inverno, e na direção NE, durante a primavera e o verão. A média anual da velocidade dos ventos é de $2,3 \mathrm{~m} / \mathrm{s}$, reduzindo no verão e intensificando - se no inverno (MATOS, 2000).

Durante o ano, o ambiente estudado passa por algumas variações justamente por conta da influência climática. No período considerado chuvoso - nos meses de Abril a Julho - surgem diversas lagoas 
intermitentes na APA. Estas alimentam o lençol freático da região e auxiliam a manutenção da cadeia alimentar, uma vez que espécies como anfíbios e insetos se desenvolvem neste período.

Nos meses de setembro a fevereiro o sol prevalece, porém há períodos curtos de chuva de períodos alternados de chuvas, justamente por conta do calor e a evaporação. Nesta época, a vegetação típica da região começa a se desenvolver e as plantas e árvores frutíferas servem de alimentos para às aves e mamíferos da região.

$\mathrm{Na}$ área do Abaeté, que é uma restinga com aparência homogênea, ocorre espaçamento entre as manchas de vegetação, que abrigam diversidade de comunidades vegetais que são separadas por lagoas e brejos costeiros ou por extensões de areias (VIANA, 1999). A fitofisionomia da vegetação varia de porte herbáceo até o arbóreo-arbustivo em algumas áreas de mata de restinga (MORAWETZ,1983). Na paisagem predominam manchas de vegetação formando moitas de diversos tamanhos que podem conter ou não folhiço em sua base, a depender da espécie de planta ou da ação do vento em áreas mais expostas (DIAS \& ROCHA, 2004).

A presença da cobertura vegetal como representadas nas figuras 2 e 3 é fundamental para manter o equilíbrio do ecossistema, fixando os sedimentos e contribuindo para a manutenção do equilíbrio morfológico. $\mathrm{Na}$ área de estudo, existe a presença de mata úmida que se estende nas depressões ligadas às lagoas, constituída por árvores de 15 a 20 metros, que são encontradas em algumas porções dentro da APA
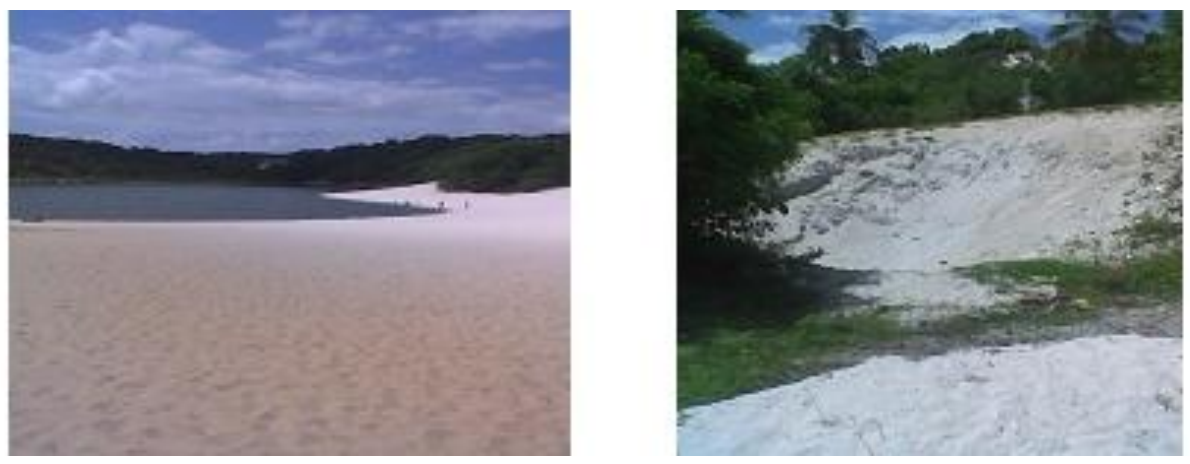
Figura 2 e 3. Cobertura vegetal na Lagoa do Abaeté

Fonte: os autores, 2011.

Segundo artigo da resolução CEPRAM n 3.023/2002, os últimos remanescentes de restinga arbórea em Salvador/BA estão localizadas na APA do Abaeté, apresentando estágios diversos de conservação, uma vez que a região está cercada por um tecido urbano degradado.

As lagoas, brejos e alagadiços são as principais características hidrográficas do ambiente de restinga investigado. Na APA do Abaeté as lagoas de maior representatividade eram alimentadas por algumas nascentes, estas que atualmente não existem mais devido a construção de grandes empreendimentos no local e que utilizam o lençol freático para abastecimento, como reforça o jornal A TARDE em matéria exibida em 17 de março de 2008:

\footnotetext{
"A utilização clandestina de água subterrânea na região da APA das Lagoas e Dunas do Abaeté é do conhecimento das autoridades públicas, mas, até hoje, não se sabe se isso compromete ou não o lençol freático. Na resolução em que aprovou o primeiro plano de manejo da APA, em 1998, o Conselho Estadual de Meio Ambiente (Cepram) determinava à Companhia de Desenvolvimento Urbano do Estado da Bahia (Conder) que adotasse medidas para "implantação de um sistema de água potável para a área abrangida pela APA, visando à diminuição da utilização de água subterrânea através de poços tubulares que vem se dando de forma descontrolada(...)". (ATARDE, 2008)

"A única ação neste sentido foi tomada no caso do Hotel Sofitel, construído há mais de 20 anos e que, somente a partir de 2000, regularizou-se junto à SRH, depois de denúncias do Grupo Ecológico Nativo de Itapuã. Apesar de a rede pública de abastecimento chegar às áreas em torno das dunas, o uso da água subterrânea permanece. Em ruas como a da Passárgada, em Itapuã, basta chegar à portaria e os porteiros não têm reserva em informar a existência de poços nas moradias, apesar de serem servidas pela água da Empresa Baiana de Águas e Saneamento (Embasa)". (A TARDE, 2008)
}

Hoje, existem pouquíssimas nascentes e os rios foram extintos restando apenas algumas lagoas e alagadiços. A principal delas é a Lagoa do Abaeté cujo espelho d'água tem diminuído de tamanho gradativamente em virtude da devastação de sua mata ciliar, da evaporação e do bombeamento de água clandestino conforme a figura 4 . 


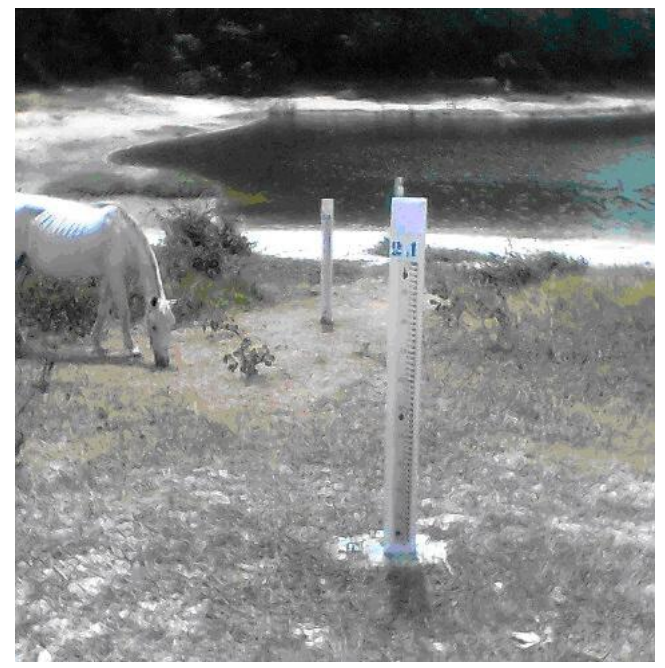

Figura 4. Diminuição do nível de água da Lagoa do Abaeté Fonte: os autores, 2011.

\section{O CASO DOS PLANOS DIRETORES DE MARINGÁ}

Durante o Século XX, o Brasil mudou sua estrutura urbana e econômica. No entanto, em decorrência do enorme crescimento demográfico, surgiu o problema do déficit habitacional. Várias medidas foram tomadas nas principais metrópoles brasileiras. Na capital baiana, destacam-se as ações de estímulo à industrialização, criação da Região Metropolitana de Salvador (RMS), instalação da exploração de petróleo no Recôncavo, Centro Industrial de Aratu (CIA) e Complexo Petroquímico de Camaçari (COPEC). Ainda, ressalvam-se a viabilização e melhoramento da acessibilidade à cidade de Salvador com a estruturação do Acesso Norte, a construção do aeroporto internacional Dois de Julho (atual deputado Luis Eduardo Magalhães), do sistema ferry-boat, e a duplicação da BR-324 (Vasconcelos, 2002). Destaca-se, também, a ação do Governo Federal na intensificação da política de ampliação da oferta de habitações, transferindo à Caixa Econômica Federal (CEF) o controle do Banco Nacional de Habitação (BNH), que, se refletiu na cidade real via o financiamento de imóveis novos ou usados à classe média nos grandes centros urbanos.

Especificamente na década de 70 foi que o processo de crescimento urbano se intensificou na cidade de Salvador e, principalmente em no bairro de Itapuã. Este bairro até então era considerado distante e 
fora dos principais eixos de crescimento da cidade. Com a criação do acesso norte, ocorreu uma crescente ocupação de algumas áreas, inclusive da região que hoje forma a APA do Abaeté.

O processo de ocupação coletiva de áreas públicas ou privadas para a moradia da população menos favorecida acompanhou igualmente os processos de consumo desenfreado dos bens naturais, com sérios impactos ao ecossistema. A ocupação habitacional desordenada causou ocupação das áreas verdes do município sobre as parcelas remanescentes das lagoas e dunas, e esta situação ocorrida na década de 80, permanece até a atualidade sem que o poder público consiga reverter o problema (OLIVEIRA, 2009).

$\mathrm{Na}$ atualidade as áreas próximas a Itapuã sofrem o impacto da segregação habitacional, e as dunas e lagoas do Abaeté são invadidas constantemente. Em 1986, quando iniciaram a delimitação da APA do Abaeté, as áreas das dunas começaram a ser ocupadas irregularmente como mostram as fotografias na figura 5.
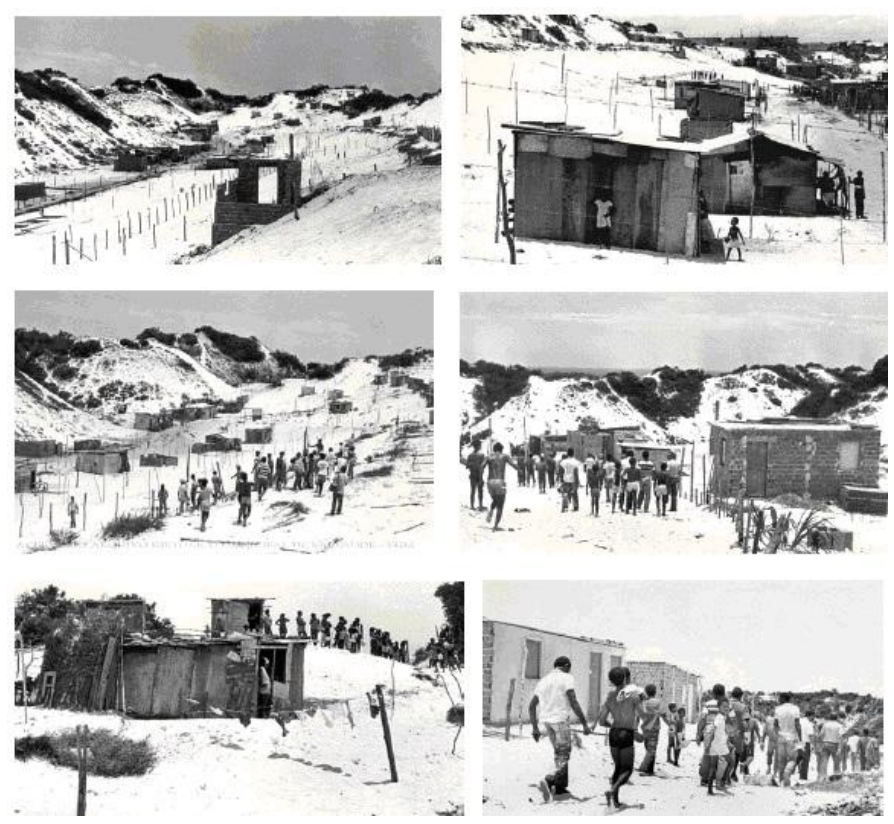

Figura 5. Ocupação irregular das áreas das dunas.

Fonte: Acervo Público Municipal, 1994. 
A caracterização da degradação não se delineia somente por conta das invasões por famílias de baixa renda. A prova disso são as invasões conhecidas como invasões do "colarinho branco" sobre terrenos públicos, que também obedecem à lógica individual do interesse imobiliário, e casas particulares de alto padrão de construção foram edificadas nas dunas e áreas verdes dentro da APA do Abaeté. O que configura um tipo ainda mais perverso de apropriação do bem comum e dos recursos naturais. As invasões "nobres" impactaram as dunas e áreas verdes da APA, englobando grandes construções residenciais e até mesmo empreendimentos turístico-comerciais (OLIVEIRA, 2009).

Este crescimento urbano é caracterizado em sua maioria justamente na faixa litorânea da APA, como pode ser observado na figura 6. 0 que comprova o interesse populacional pelas construções próxima do mar e das principais vias do entorno da APA do Abaeté.

Com o passar dos anos, novas áreas foram surgindo e ampliando a área urbana na região, o que na atualidade pode-se configurar através dos três principais eixos sociais distintos de convivência, tanto dentro, como no entorno da APA do Abaeté. Tais eixos de convivência são configurados em três em classes, justamente por conta dos valores e tipos de propriedades encontradas na região. A primeira classe, considerada como "classe alta" (acima de seis salários mínimos) está localizada na parte litorânea da APA, margeando as ruas Professor Souza Brito, Palmas de Monte Santo, General Severino Filho, José Augusto Tourinho Dantas até os limites finais na Praia de Ipitanga podendo ser identificada através dos condomínios luxuosos e os grandes empreendimentos com total conforto e ampla infra-estrutura. As áreas consideradas como "classe média" (ocupada por famílias com renda superior a três salários mínimos), compreendem-se em sua maioria grande quantidade de residências que foram transformadas em estabelecimentos comerciais que atendem a demanda turística do bairro. São os locais como: o largo das baianas, a Igreja de Itapuã e a feira antiga e o Penedo. As áreas consideradas como da "classe baixa" (entre um e três salários mínimos) referem-se as áreas anteriormente destinadas à construção de loteamentos que em contrapartida não se desenvolveram. Além disso, as "famosas" invasões como a Baixa da Soronha, Baixa do Dendê, Alto da Bela Vista e Alto do Macaco fazem parte deste contexto, sendo que estas áreas não possuem infraestrutura urbana. 
Na figura 6, há uma faixa de 300 metros no entorno da APA do Abaeté a qual apresenta um padrão urbanístico os quais separados em classes exercem uma forte pressão nas áreas ainda não ocupadas dentro da APA.

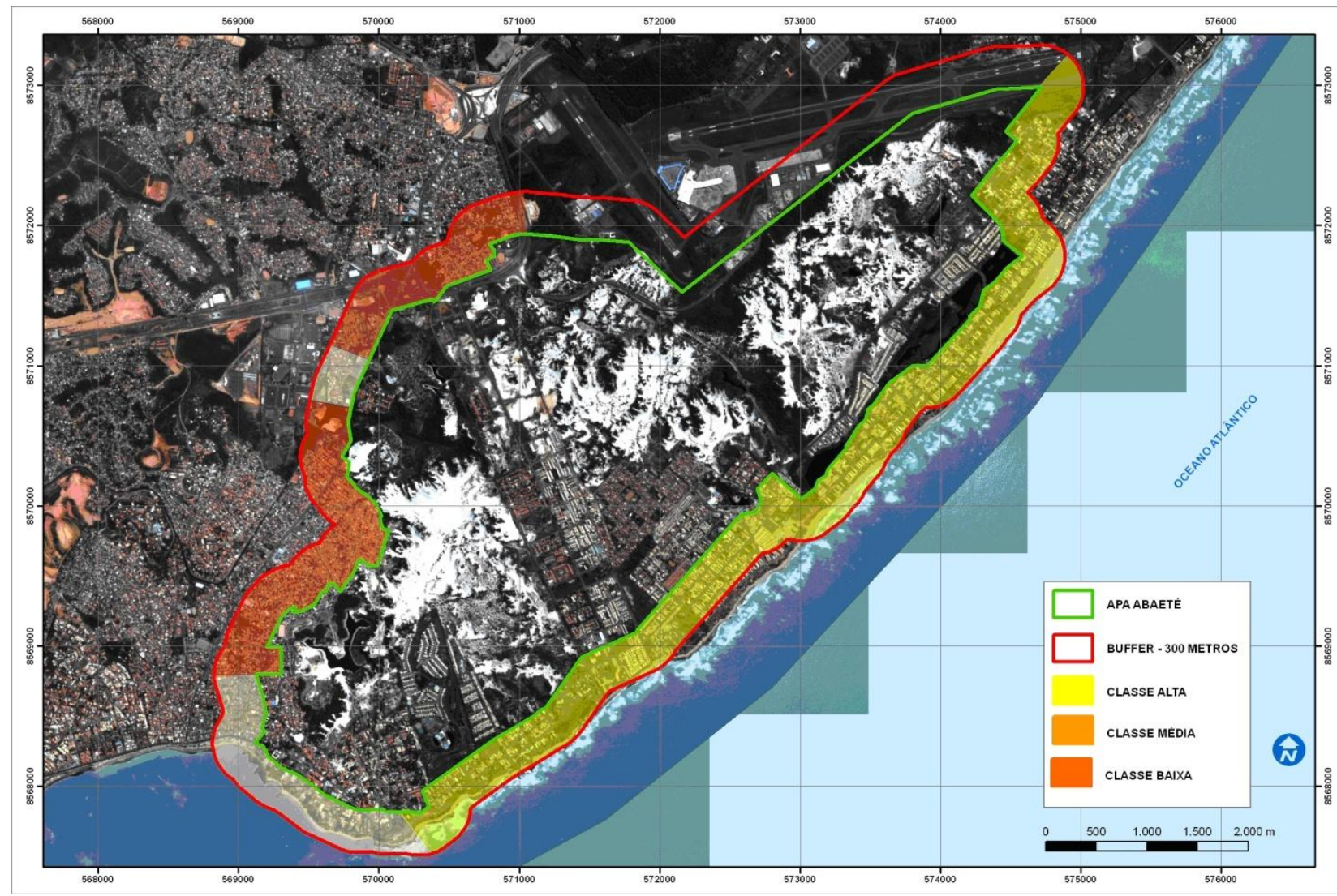

Figura 6. Representação temática das classes sociais no entorno da APA do Abaeté.

Fonte: CONDER, (2010).

\section{ANÁLISE DOS ZONEAMENTOS E SEUS DESDROBAMENTOS NA APA DO ABAETÉ}

O Parque do Abaeté foi inaugurado no dia 3 de setembro de 1993, situado dentro da APA do Abaeté composto por dunas, lagoas e vegetação nativa. O Parque Metropolitano do Abaeté é um dos maiores centros de lazer ecológico do Nordeste, com uma área urbanizada de 225 hectares, criação baseada na preservação ambiental da área.

Nesse sentido, o Governo do Estado da Bahia, no uso de suas atribuições com fundamento no Art. $8^{\circ}$ da Lei n ำ 6.902/1981 atribuem ao Poder Executivo, quando houver relevante interesse público, 
poderá declarar determinadas áreas do território nacional como de interesse para a proteção ambiental, a fim de assegurar o bem-estar das populações humanas e conservar ou melhorar as condições ecológicas locais (LEI FEDERAL DO BRASIL n 6.902, 1981).

Assim, considerando que as ações antrópicas temporais incidem na área do Abaeté, pela sua característica predatória, podendo conduzir à desfiguração e provavelmente destruição do ecossistema na única área de restinga (dunar/lagunar) da capital baiana; considerando que a preservação das Lagoas e dunas do Abaeté não só atenderá a todos aqueles que, desde 1983, vêm solicitando sua permanência bem assim resgatando, para o povo da Cidade da Bahia, uma área que já em 1552 lhe fora doada por Tomé de Souza; considerando que a atuação do Estado ampliando as ações do Município do Salvador sobre tal região, dando-lhe inclusive uma normatividade mais abrangente sobre o ambiente, entendido este como o conjunto de condições, leis, influências e interações de ordem física, química e biológica, que permite abrigar e rege a vida em todas as suas formas; considerando que cabe ao Estado a segurança e a proteção do meio ambiente, já que patrimônio público de uso coletivo. (DECRETO N³51, 1987: p. 01).

Desta forma, ficou-se decretado no dia 22 de Setembro de 1987 pelo então Governador Waldir Pires a criação da Área de Proteção Ambiental - APA - das Lagoas e Dunas do Abaeté, com 1.800 há (um mil e oitocentos hectares), cujo direito de propriedade fica assim condicionada:

\footnotetext{
... estarão sujeitas às normas de proteção ambiental estabelecidas pelo Conselho Estadual de Proteção Ambiental - CEPRAM, sem prejuízo do fixado na legislação do Município de Salvador. O Conselho Estadual de Proteção Ambiental - CEPRAM, no prazo de 180 (cento e oitenta) dias, baixará instruções com vistas à execução deste Decreto. O Centro de Recursos Ambientais - CRA fiscalizará e supervisionará a Área de Proteção Ambiental das Lagoas e Dunas do Abaeté, harmonizando suas ações com as da Prefeitura Municipal do Salvador e o Instituto do Patrimônio Artístico e Cultural da Bahia - IPAC. O Centro de Recursos Ambientais - CRA poderá firmar convênios com entidades públicas e privadas, para cumprimento do disposto neste Decreto. (DECRETO N³51, 1987: p. 02)
}

Institucionalizada a APA do Abaeté que posteriormente passou a ser controlada e fiscalizada pela CONDER e atualmente as fiscalizações tanto da APA quanto do parque do Abaeté ficam a cargo da Secretaria de Meio Ambiente (SEMA). 
O primeiro zoneamento foi realizado em 1993, subdividindo a APA em apenas três áreas ecológicas econômicas (Figura 7): a ZPP (Zona de Preservação Permanente), a ZOC I (Zona de Ocupação Controlada I) e a ZOC II (Zona de Ocupação Controlada II). A ZPP é destinada a uma área onde as formas de vegetação natural, a fauna, os recursos hídricos, assim como sua morfologia - também natural - deverão se integralmente preservadas (DECRETO, n. 2.540/1993). As outras duas áreas ZOC I e ZOC II são caracterizadas como áreas de ocupação já consolidadas, de uso predominantemente residencial, rarefeita, parcial ou totalmente ocupada, continuando seu processo de ocupação sujeito a parâmetros ambientais (DECRETO 2.540, 1993).

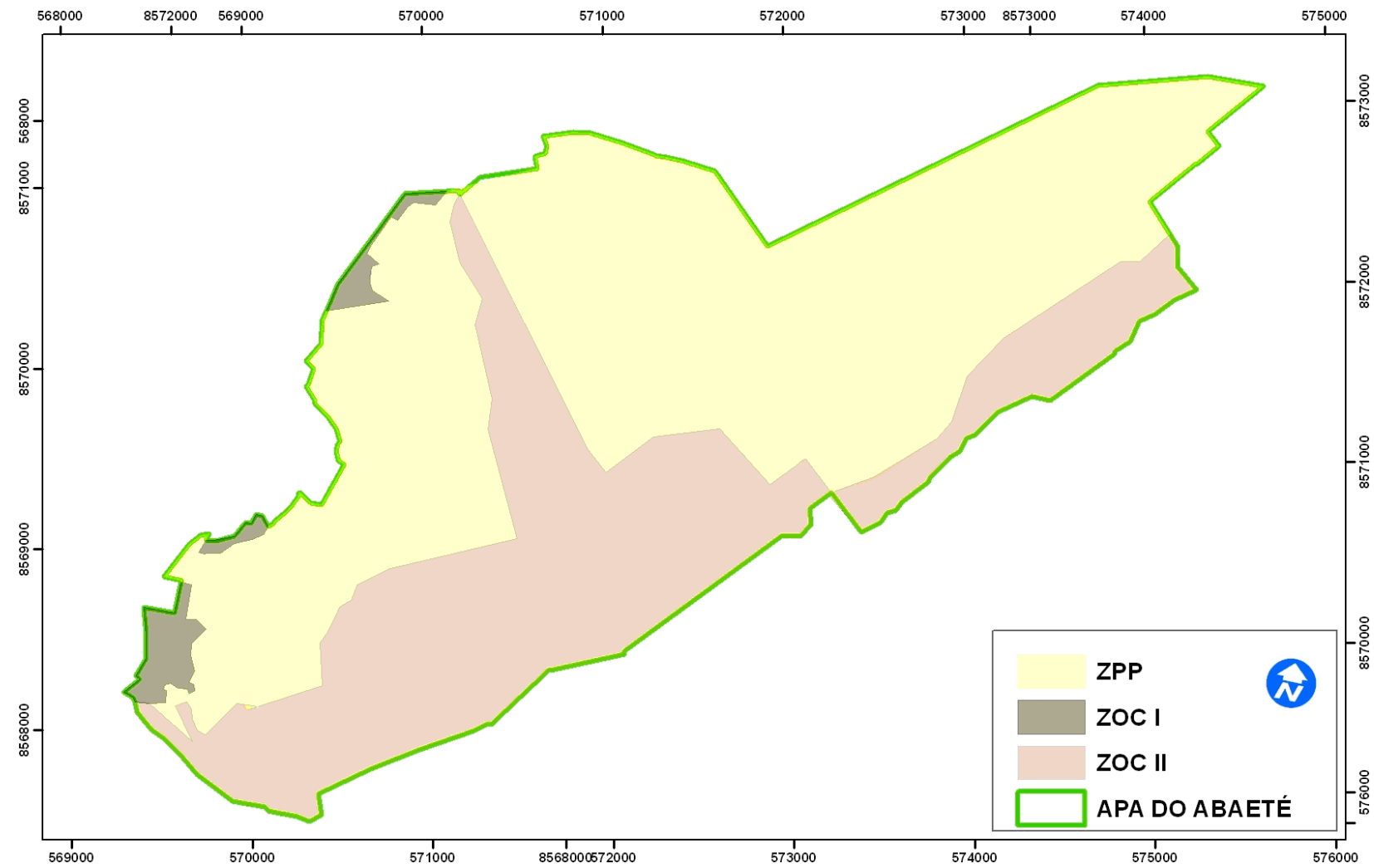

Figura 7. Áreas ecológicas econômicas na APA do Abaeté.

Fonte: CONDER, 1993.

Todavia, em 1997 com o objetivo de redefinir o ZEE, visando uma incorporação de novos territórios em busca da revitalização da orla atlântica de Salvador, e com a tentativa de atrair novos investimentos para região do Abaeté. A Companhia de Desenvolvimento Urbano do Estado da Bahia CONDER, elaborou um novo plano de manejo um novo Zoneamento da Área de Proteção Lagoa e 
Dunas do Abaeté, sendo este aprovado através da Resolução 1.660 de 22 de maio de 1998 (CEPRAM, 1998).

Neste novo zoneamento ampliou-se de três zonas ecológicas econômicas para doze zonas (Figura 8). Todas as novas áreas ganharam novos conceitos, especialidades, parâmetros, categorias, bem como 0 estabelecimento de diretrizes

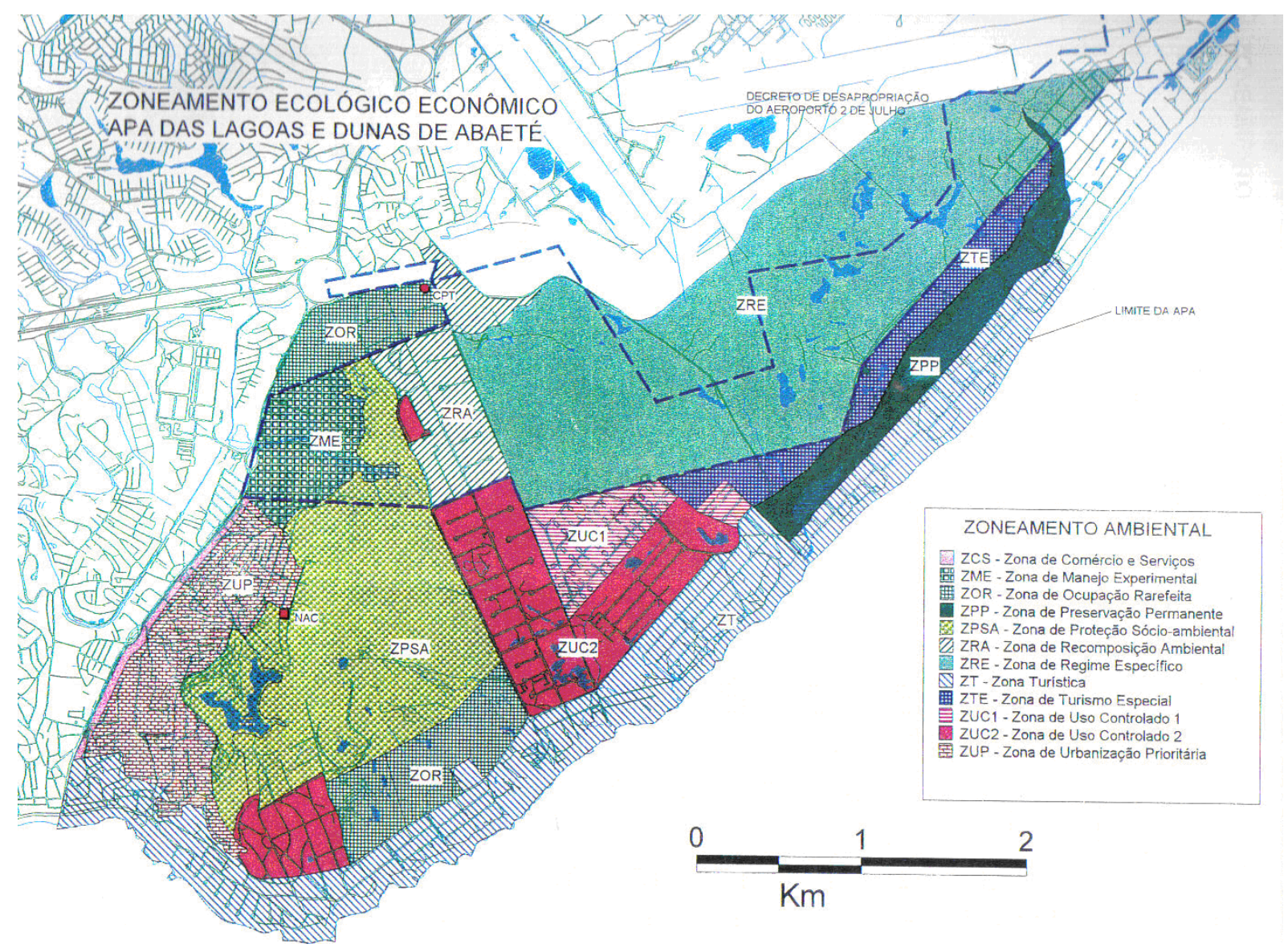

Figura 8. Ampliação das zonas ecológicas econômicas Fonte: CONDER, 1997.

Assim, o Zoneamento Ecológico Econômico da Área de Proteção Ambiental das Lagoas e Dunas do Abaeté é constituído pelas seguintes zonas:

a) Zonas de Preservação 
ZRE - Zona sob Regime Específico: utilização condicionada a estudos específicos determinados pelos órgãos ambientais e a entidade administradora da APA.

ZPP - Zona de Preservação Permanente: implantação de programas de proteção e controle

b) Zonas de Conservação

ZOR - Zona de Ocupação Rarefeita: toda atividade a ser implantada deverá se submetida à EIA/RIMA.

ZME - Zona de Manejo Experimental: implantação de projetos produtivos para envolvimento da comunidade e horto.

ZRA - Zona de Recomposição Ambiental: articulação com setores empresariais para patrocínio dos trabalhos de pesquisa cientifica e recomposição.

ZPSA - Zona de Proteção Sócio Ambiental: implantação de programas de educação ambiental e turismo ecológico.

c) Zonas de Uso

ZPSC - Zona de Proteção Sócio-Cultural: implementação de programas de apoio ao desenvolvimento turístico, a partir de financiamento de estrutura de comercio e serviços.

ZT - Zona Turística: incentivo a empreendimento na área de turismo, propiciando aumento de gabarito e diminuição das pressões sobre ecossistemas frágeis.

ZUC I - Zona de Uso controlado I: deverão ser implementados mecanismos de controle e fiscalização do uso do solo nestas áreas.

ZTE - Zona de Turismo especial: incentivo a empreendimentos na área de turismo com a obrigatoriedade de um estudo preliminar de impacto ambiental.

ZUC II - Zona de Uso Controlado II: deverão ser implementados mecanismos de controle e fiscalização do uso do solo nestas áreas.

ZUP - Zona de Urbanização Prioritária: implantação de programas emergenciais de infra estrutura urbana.

ZCS - Zona de Comércio e Serviços: implantação de infraestrutura e incentivo a atividade comercial. 
Com isto, o novo Zoneamento Ecológico Econômico da Área de Proteção Ambiental das Lagoas e Dunas do Abaeté, promoveria o desenvolvimento sustentável a partir da normatização e controle do uso do solo, além da implementação de programas de desenvolvimento econômico centrados em uma atividade turística de baixa densidade, levando em conta os elementos definidores da Unidade de Conservação.

Neste caso, o que contrapõem tais objetivos é que as principais Zonas de Preservação (ZPP e a ZRE) passaram a ter uma nova delimitação, a ZPP passou a integrada a antiga ZOC II que em 1993 possuía uma característica na qual era permitida a ação antrópica. Outro fator relevante circunda justamente na ZRE, área a qual foi autorizada a ampliação do aeroporto internacional através de um decreto, gerando dúvidas quanto à área que é de proteção permanente e mesmo sim autorizadas a ampliação de uma obra de grande impacto ambiental.

Após cinco anos surgiu a necessidade da realização de algumas modificações. Possivelmente devido à expansão urbana e à pressão da especulação imobiliária na região da APA do Abaeté. Bairros como Stella Mares e Praia do Flamengo foram valorizados por conta da construção de diversos condomínios de classe alta, em contrapartida, as ocupações irregulares aumentaram, mesmo com a fiscalização dos órgãos competentes.

Desta forma, com o objetivo de assegurar os remanescentes de restinga e o sistema de dunas e lagoas, e assegurar o desenvolvimento econômico com ênfase na atividade turística voltada para o ecoturismo, o Conselho Estadual de Meio Ambiente - CEPRAM nos usos de suas atribuições através da Resolução $\mathrm{n}^{\circ} 3.023$ de 20 de setembro de 2002 decretou um novo ZEE para a APA do Abaeté (Figura 9). E mais uma vez, os parâmetros ambientais foram readequados devido ao rápido processo de degradação ambiental na região. 


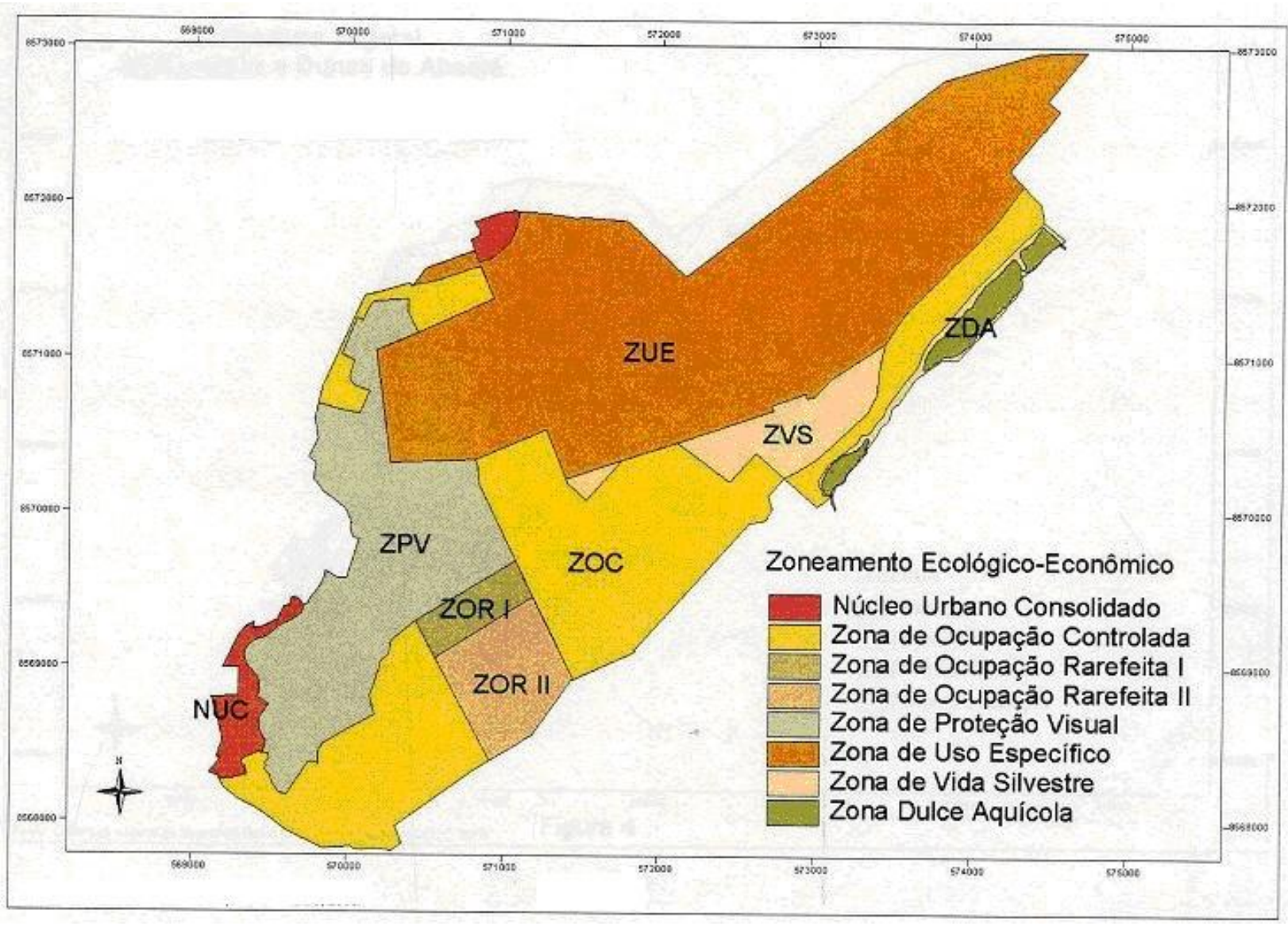

Figura 9. Novo ZEE para a APA do Abaeté Fonte: SEMARH/DUC, 2002.

Com estas readequações foram alteradas a quantidade de áreas, diminuindo de doze zonas para oito zonas ecológicas econômicas (RESOLUÇÃO $\mathrm{n}^{\circ} 3.023$ de 20 de setembro de 2002), conforme apresentadas abaixo:

ZPV - Zona de Proteção Visual: A preservação do sistema dunar e a sua vegetação admitem apenas atividades de pesquisa científica, educação ambiental, visitação pública e ecoturismo, sendo permitida apenas a implantação de pequena estrutura de apoio à visitação. Proibido qualquer parcelamento do solo e a supressão de vegetação fixadora das dunas Proibição do tráfego de veículos automotores. 
ZVS - Zona de Vida Silvestre: Preservação dos ecossistemas admitindo-se apenas atividades de estudo e pesquisa científica, educação ambiental, ecoturismo e intervenções que promovam a recomposição e revitalização das lagoas.

ZUE - Zona de Uso Específico: Proteção do ambiente natural. Turismo ecológico controlado. Atividades de visitação. Pesquisa científica e desenvolvimento de tecnologias para utilização sustentável. Futura ampliação do aeroporto, estando sua utilização condicionada a Estudos de Impacto Ambiental - EIA e determinações estabelecidas pelos órgãos ambientais e outras entidades.

ZOC - Zona de Ocupação Controlada: Uso residencial turístico, serviços ou comercial. Gabarito máximo de $08 \mathrm{~m}$ ou 02 pavimentos.

ZOR I - Zona de Ocupação Rarefeita I: Uso turístico, esportivo e recreativo;

ZOR II - Zona de Ocupação Rarefeita II: Uso turístico, recreativo, esportivo, serviços, comercial, ou residencial. Gabarito máximo 08 m ou 02 pavimentos.

NUC - Núcleo Urbano Consolidado: Uso residencial, serviços ou comercial. Deverá atender o que estabelece a Legislação de ordenamento do uso e ocupação do solo do município de Salvador.

ZDA - Zona Dulce Aqüícola: Permite-se a pesca respeitando a legislação vigente e o período de defeso, estabelecido pelo IBAMA. Proibido o lançamento de qualquer substância tóxica, a exemplo de óleos, graxas, etc. Proibido o lançamento de esgoto doméstico "in natura". Proibida a implantação de equipamentos como marinas, tanques rede, etc., sem a autorização dos órgãos competentes. Proibida a retirada de água sem o documento de outorga. Permitem-se atividades de lazer e turismo com a aprovação do órgão gestor da APA. 
Diante deste novo zoneamento, a expectativa ficou por conta da conservação deste ecossistema, todavia, percebe-se que nos parâmetros ambientais do ZEE de 2002 publicados em 2005, que houve uma maior preocupação com relação às áreas que sofreram degradação pela ocupação irregular mesmo com o zoneamento de 1997, ano que foi o ponto de partida para a aceleramento da degradação na região.

Entendendo que o ZEE surge como principal instrumento regulador de uma Área de Proteção Ambiental, e para uma prevista efetivação da legislação em determinadas áreas, sua influência pode determinar ou possibilitar casos de equilíbrio ou desequilíbrio ambiental, sendo que em alguns casos podem ser irreversíveis.

Para facilitar tal análise, fez-se necessário um agrupamento das ZEE nos seus respectivos zoneamentos, levando em consideração os seus conceitos apresentados e mesclando-as em Zonas Urbanizáveis (áreas que poderia haver construções) e Zonas Não-Urbanizáveis (áreas que não poderiam haver construções).

Neste contexto, a APA do Abaeté apresenta historicamente apropriação de seu espaço na influência de seus zoneamentos, principalmente entre os anos 1992 e 2002, período que ocorreu a primeira reformulação do zoneamento de 1993 para o de 1997. Nessa reformulação foram incorporadas áreas para a construção de condomínios fechados e a desapropriação de algumas áreas, consideradas como “invasões" de famílias de baixa renda, nas mediações da Lagoa do Abaeté.

As áreas consideradas não urbanizadas em 1992, antes do zoneamento de 1997 e urbanizadas em 2002 correspondiam a 8,93\% - cerca de 110,93 hectares dos 1.241 ha de toda a APA - o que vale chamar a atenção é que no mesmo período a referida área ganhou cerca de 2,09\% (26,04 hectares) de áreas urbanizadas em 1992 e passaram a ser não urbanizadas em 2002. 
No entanto, entre 2002 e 2010 houve um novo zoneamento reformulando todas as suas zonas específicas, com áreas consideradas anteriormente como zonas não urbanizáveis tornando-se zonas urbanizáveis e vice-versa, atendendo efetivamente a especulação imobiliária da região, uma vez que as construções dos condomínios e villages eram constantes.

Contudo, ao analisar o mapa das classes sociais (Figura 6) pode-se perceber que o crescimento dentro da APA foi significante na faixa litorânea, que apresentou até 2010 um crescimento 29,08\%, em toda sua extensão (361 ha ao todo). Sendo assim, ocorreu um aumento de 20,15\% quando comparado aos anos anteriores.

Em contrapartida, as zonas que eram tidas como urbanizadas e passaram a ser não urbanizadas também apresentaram decréscimo no seu percentual de áreas com relação aos anos de 1992-2002, passando para apenas 0,24\% entre 2002 e 2010 (Tabela 1 e Figuras 10 e 11).

Neste contexto, a tabela 1 apresenta os números e percentuais entre os anos comparados (1992-2002 e 2002-2010), apresentando os percentuais relativos as áreas que foram reduzidas e/ou regeneradas na área de estudo. Vale ressaltar na apresentação desses dados que em um período de 18 anos a APA do Abaeté teve uma redução de 75,35 ha de sua área.

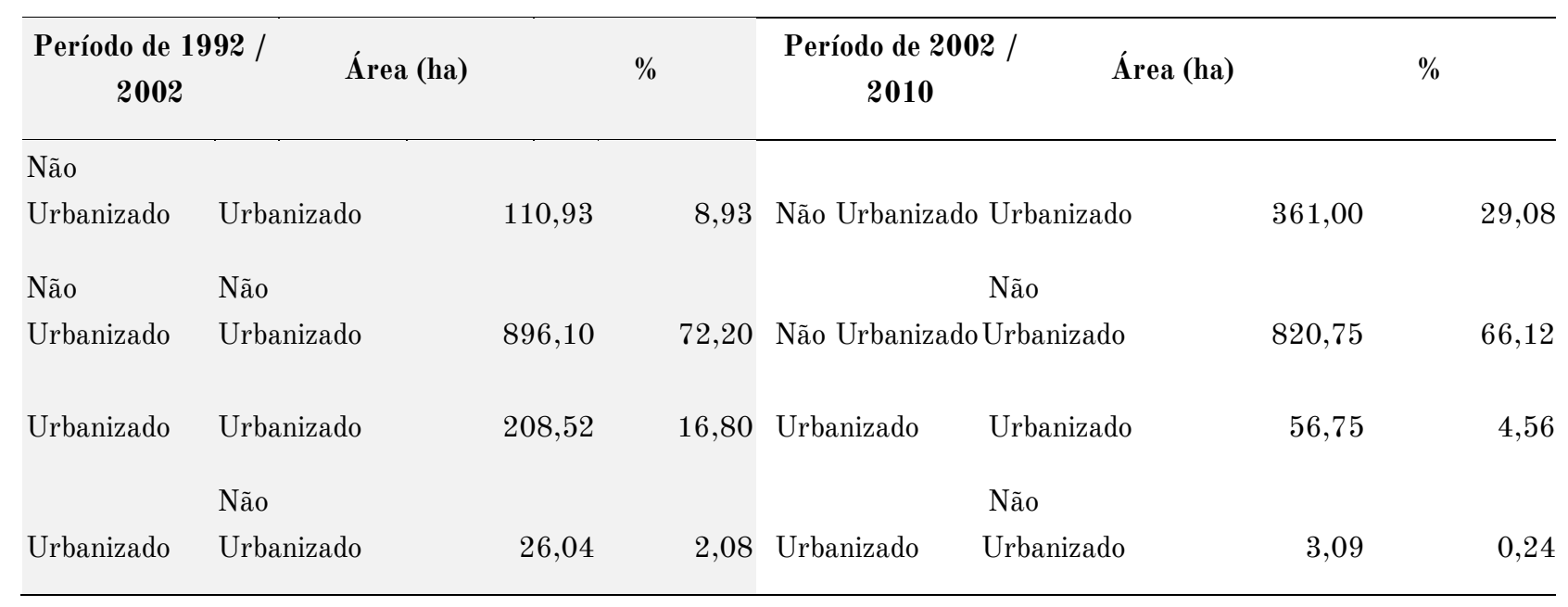

Tabela 1. Dinâmica espacial na área de estudo. Fonte: os autores, 2012. 


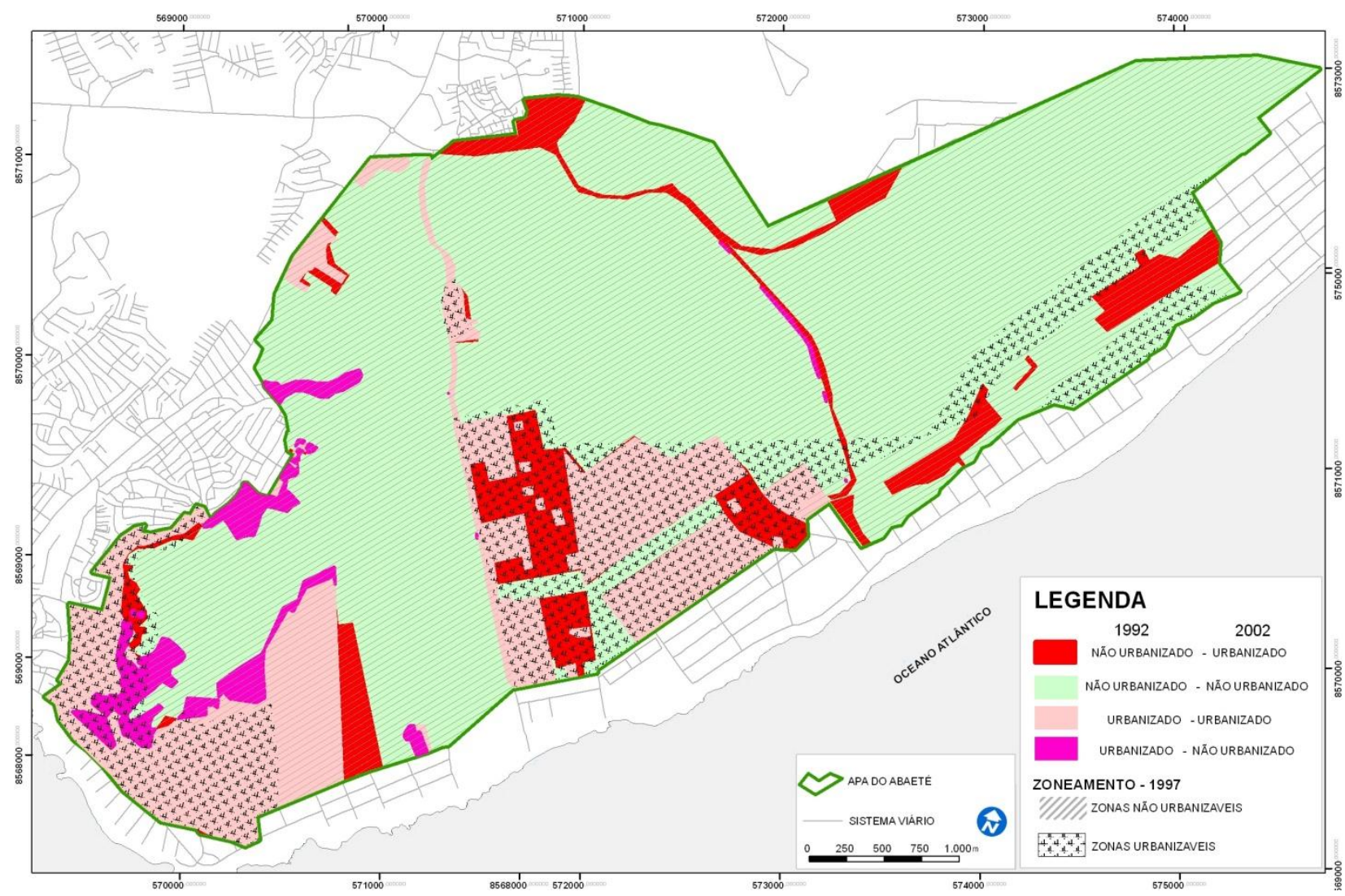

Figura 10. Mapa comparativo da cobertura do solo 1992 - 2002 Fonte: os autores, 2011.

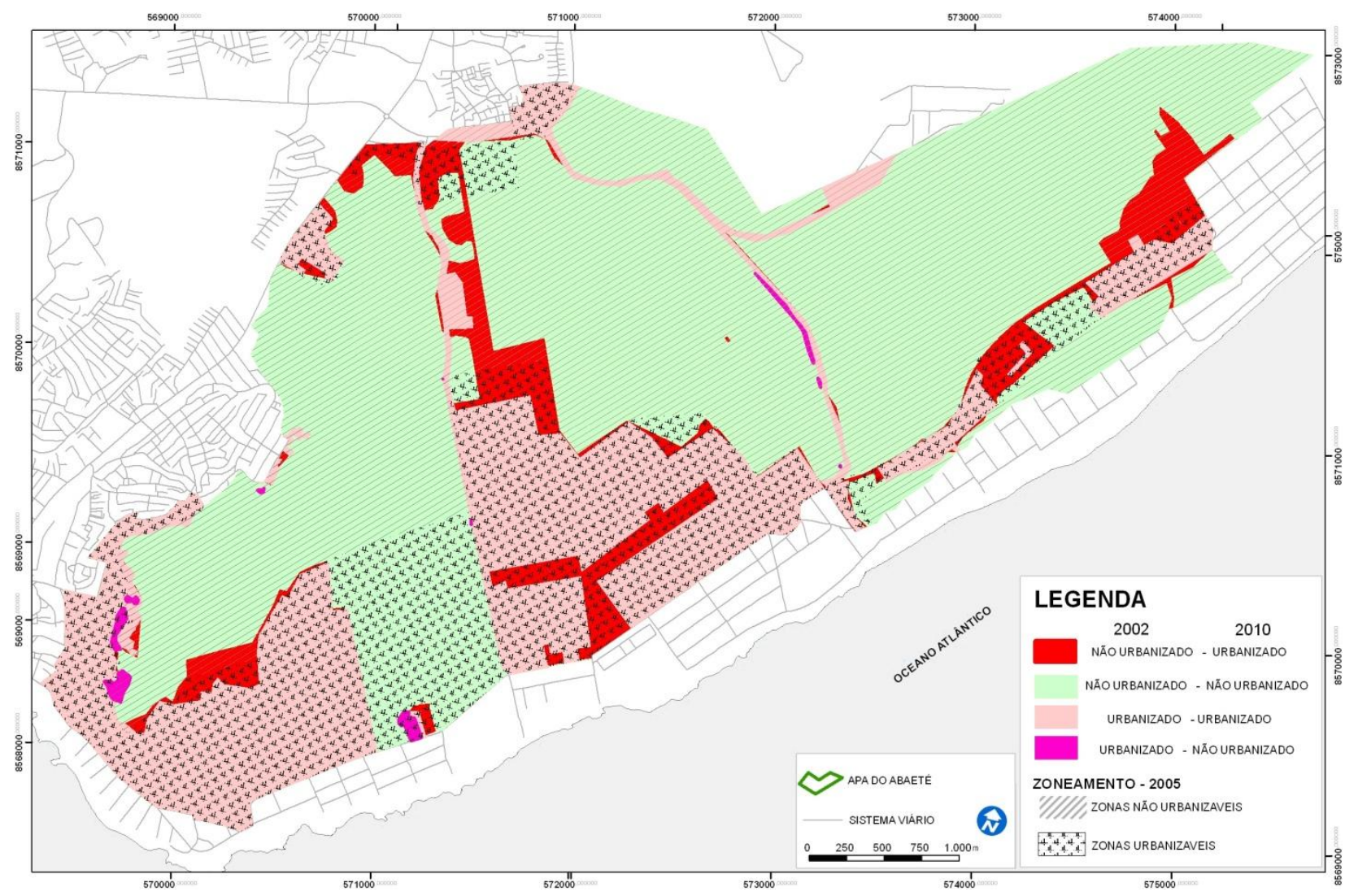


Figura 11. Mapa comparativo da cobertura do solo 2002 - 2010

Fonte: os autores, 2011.

Os dados apresentados na tabela 1 e os mapas (figuras 10 e 11) evidenciam que os principais problemas ambientais encontrados na APA do Abaeté estão associados ao crescimento urbano, sem controle ou fiscalização efetiva dos órgãos competentes. O que os números apresentam sucinta reflexão acerca da importância de um ZEE rigoroso. O zoneamento é considerado um instrumento passivo e só obtém efetiva função quando os órgãos responsáveis possuem instrumentos para viabilizar o funcionamento.

\section{CONSIDERAÇÕES FINAIS}

Os problemas enfrentados na APA do Abaeté são graves e perduram por quase cinquenta anos. Em busca da sustentabilidade sugere-se a criação do uso social do ambiente preservado através de um uso comunitário do espaço, instigando através da educação ambiental a criação da identidade da população com o território como cidadão. Sugere-se assim através da Educação Ambiental, um processo que consista em propiciar às pessoas uma compreensão crítica e global do ambiente. Assim, o conceito de desenvolvimento sustentável deve ser trabalhado com urgência e em todas as classes sociais que ocupam tanto a APA quanto seu entorno, no intuito de enfrentar os problemas temporais ambientais. Acrescenta-se ainda a criação de uma proposta reflexiva acerca do desenvolvimento de zonas de amortecimento dentro da APA, ocasionando uma melhora na pressão de fronteira e criando obviamente zonas de conforto nas áreas protegidas.Constatou-se que não basta apenas o apoio e incentivo dos órgãos competentes, mas há necessidade urgente de serem estabelecidas práticas e políticas ambientais que englobem todas as camadas sociais, fortalecendo as Organizações Não Governamentais (ONG'S). Promovendo a consciência ambiental da comunidade local aos visitantes da área (turistas), ambulantes, estudantes e empresários. Com isso, poder-se-ia alcançar um desenvolvimento sócio-econômico-cultural sem degradar os componentes ambientais da APA.

\section{REFERÊNCIAS}


BURRoUgh, P. A. \& MCDONNELL, R. A. Principles of Geographical Information Systems. Oxford: Oxford University Press. 1998.

CÂMARA, G. et al. Anatomia de Sistemas de Informação Geográfica. São José dos Campos: INPE. 2001.

CONDER, Área de Proteção Ambiental Litoral Norte: Proposta de Programa / Projetos (Mata Atlântica e seus ecossistemas associados). Salvador: CONDER, 2003.

CONDER. Zoneamento Ecológico Econômico da Area de Proteção Ambiental das Lagoas e Dunas de Abaeté. Salvador: CONDER, 1997

DIAS, E. J. .R.. \& ROCHA, C. F. D. Os Répteis nas restingas da Bahia: Pesquisa e Ações para a sua Conservação: Instituto BIOMAS. Rio de Janeiro, 2005.

INMET. Gráficos Climatológicos. <http://www.inmet.gov.br>. Acessado em 12/10/2014

JACOBS, Jane. Morte e vida de grandes cidades. São Paulo: Martins Fontes, 2000.

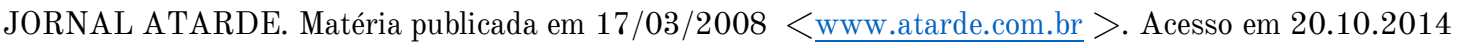

JUERGENSMEYER, Julian Conrad; ROBERT, Thomas. Land use planning and development regulation law. St. Paul: Thomson West, 2003.

OLIVEIRA, Orlando José Ribeiro de. Turismo, cultura e meio ambiente: estudo de caso da Lagoa do Abaeté em Salvador Bahia. 2009. 136 f., il. Dissertação (Mestrado em Desenvolvimento Sustentável)-Universidade de Brasília, Brasília, 2009.

PEREIRA, Gilberto Corso; SILVA, Barbara Christine Nentwig. Geoprocessamento e Urbanismo. In: GERARDI, Lucia Helena de Oliveira; MENDES, Iandara Alves. (Org.). Teoria, Técnicas, Espaços e Atividades: temas de Geografia contemporânea. Rio Claro: UNESP, 2001, p. 97-137. Disponível em:

http://homepage.mac.com/gilbertocorso/textos/Geo\%20e\%20Urbanismo. Acesso em: 26.10.2014

ROSA, R. Geotecnologias na geografia aplicada. Revista do Departamento de Geografia, 16 (2005) 81-90. Disponível em: http://www.geografia.fflch.usp.br/publicacoes/RDG/RDG_16/Roberto_Rosa.pdf 